extubated within 6 hours after surgery. Her recovery was uneventful. She was discharged on postoperative day 7 with oral anticoagulation (international normalized ratio 2.5) and without oxygen substitution. A follow-up CT scan showed normal perfusion of the homograft (Figure 1, B). Eight months after the resection, the patient is recurrence-free.

\section{DISCUSSION}

The diagnosis of PA sarcoma is often not correctly established before surgery, ${ }^{4}$ as described in our case. Even though magnetic resonance imaging and positron emission tomography did not demonstrate any signs of malignancy, intraoperative and postoperative histologic examination showed relapse of the sarcoma. It is without doubt that even advanced and unique diagnostics, such as magnetic resonance imaging and positron emission tomography scanning once, again failed to distinguish pulmonary embolism from intravascular sarcoma. A definitive diagnosis of PA sarcoma requires the pathologic examination of tissue obtained by intravascular, percutaneous, or surgical biopsies. ${ }^{5}$
In this emergency situation, we were able to resect a sarcoma of the PA, which was mimicking fulminant acute pulmonary embolism with tumor-free resection margins, and to solve the acute problem. Improvements are required to establish the diagnosis of this disease correctly. Nevertheless, this case is rare and it shows the feasibility of resection of recurrent sarcomas in areas such as the great vessels even after extensive previous resection.

\section{References}

1. Mandelstamm M. Über primäre Neubildungen des Herzens. Virchows Arch Pathol Anat. 1923;245:43-54

2. Delany SG, Doyle TC, Bunton RW, Hung NA, Joblin LU, Taylor DR. Pulmonary artery sarcoma mimicking pulmonary embolism. Chest. 1993;103:1631-3.

3. Kramm T, Gaumann A, Heussel CP, Dahm M, Oelert H, Mayer E. [Surgica management of pulmonary artery sarcoma.] Dtsch Med Wochenschr. 2001;126: 1423-7.

4. Parish JM, Rosenow EC 3rd, Swensen SJ, Crotty TB. Pulmonary artery sarcoma: clinical features. Chest. 1996;110:1480-8.

5. Manso L, Alvarez E, Quintela M, Cortes-Funes H, Hitt R. Primary pulmonary artery sarcoma: report of three cases and review of the literature. Clin Lung Cancer. 2007;8:277-81.

\title{
Mitral annuloplasty in an infant with Barth syndrome and severe mitral insufficiency: First case report and determination of annular diameter
}

Shu-Chien Huang, MD, ${ }^{\mathrm{a}}$ En-Ting Wu, MD, ${ }^{\mathrm{b}}$ Shuenn-Nan Chiu, MD, ${ }^{\mathrm{b}}$ Wuh-Liang Hwu, MD, ${ }^{\mathrm{c}}$ Mei-Hwan Wu, MD, PhD, and Shoei-Shen Wang, MD, $\mathrm{PhD},{ }^{\mathrm{a}}$ Taipei, Taiwan

Barth syndrome, an X-linked recessive disorder, is caused by mutations in the taffazin gene (TAZ) at $\mathrm{Xq} 28$, leading to severe cardiolipin deficiency in the mitochondrial membrane. ${ }^{1}$ The most common presentation is cardiomyopathy in infancy, including left ventricular (LV) dilation, hypertrophy, and noncompaction, with congestive heart failure.

In the case of refractory heart failure, a heart transplant is considered to be required. ${ }^{2}$ We performed a successful mi-

\footnotetext{
From the Departments of Surgery, ${ }^{\mathrm{a}}$ Pediatrics, ${ }^{\mathrm{b}}$ and Genetics, ${ }^{\mathrm{c}}$ National Taiwan University Hospital, Taipei, Taiwan.

Received for publication Nov 25, 2007; accepted for publication Jan 17, 2008.

Address for reprints: Shoei-Shen Wang, MD, PhD, Department of Surgery, National Taiwan University Hospital, 7 Chung-Shan S Rd, Taipei 100, Taiwan (E-mail: sswang@ha.mc.ntu.edu.tw).

J Thorac Cardiovasc Surg 2008;136:1095-7

$0022-5223 / \$ 34.00$

Copyright (C) 2008 by The American Association for Thoracic Surgery

doi:10.1016/j.jtcvs.2008.01.031
}

tral valve repair on an infant with Barth syndrome with a presentation of cardiogenic shock. We describe the techniques and consideration for mitral valve repair for this infant.

\section{CLINICAL SUMMARY}

An 11-month-old boy had Barth syndrome, which had been diagnosed during his early infancy. Echocardiography revealed LV noncompaction with hypertrophy and impaired systolic function (LV ejection fraction 36\%) with severe mitral regurgitation (MR). He was treated with furosemide, captopril, and aspirin. He was also on the waiting list for a heart transplant.

The patient was admitted to the intensive care unit with the impression of cardiogenic shock. Echocardiography showed severe MR with dilated left atrium and LV (Figure 1, A). A short period of cardiac massage was required for profound shock and bradycardia; the cardiac surgeon was then 

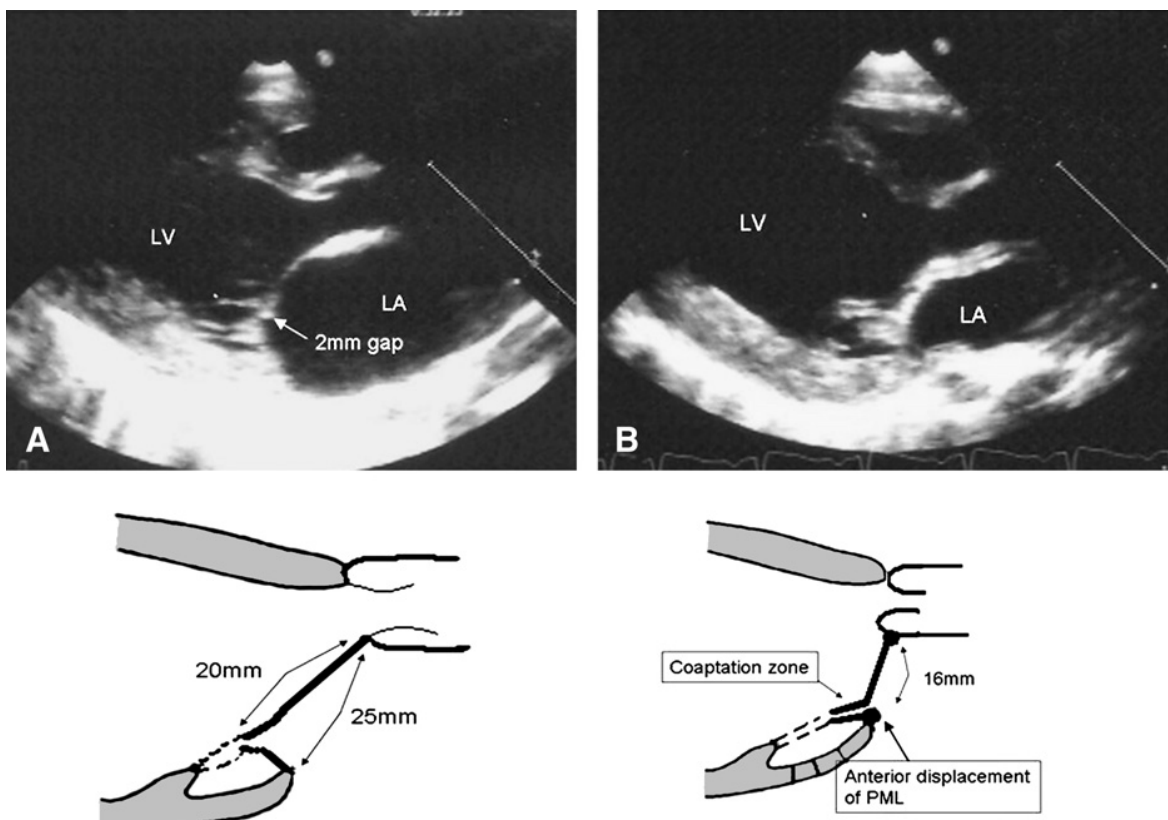

FIGURE 1. Echocardiography. A, Preoperative echocardiography revealed dilated left atrium $(L A)$, left ventricle $(L V)$, and gap between anterior and posterior mitral leaflets (arrow). B, Three months after surgery, left atrium $(L A)$ and left ventricle $(L V)$ had decreased in size, and minimal mitral valve regurgitation was noted. Single functional anterior mitral leaflet was consistent with our preoperative planning. $P M L$, Posterior mitral leaflet.

immediately consulted regarding placement of a mechanical circulatory support bridge to transplant. We offered mitral valvoplasty as an alternative treatment, because donors for infant heart transplants is extremely rare in our country. Before surgery, the patient's heart rate was 170 beats/min, and his blood pressure was only $60 / 30 \mathrm{~mm} \mathrm{Hg}$, despite an infusion of dopamine $(10 \mu \mathrm{g} /[\mathrm{kg} \cdot \mathrm{min}])$ and milrinone $(0.5 \mu \mathrm{g} /$ $[\mathrm{kg} \cdot \mathrm{min}])$. After cardiopulmonary bypass, the mitral valve was exposed through the dilated left atrium. We made a partial ring (Figure 2) from an expanded polytetrafluoroethylene patch (GORE-TEX cardiovascular patch, 0.4-mm thickness; W.L. Gore \& Associates, Inc, Flagstaff, Ariz) for reductive annuloplasty. The inner diameter was 16 $\mathrm{mm}$, and the width was $2 \mathrm{~mm}$. With interrupted 3-0 braided polyester suture (Ethibond; Ethicon, Inc, Somerville, NJ), the expanded polytetrafluoroethylene ring was fixed on the

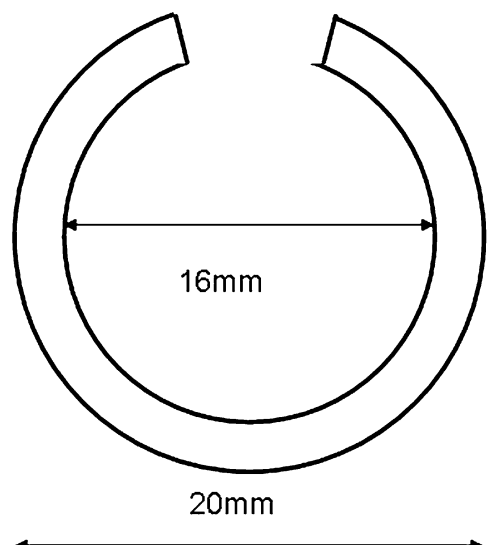

A

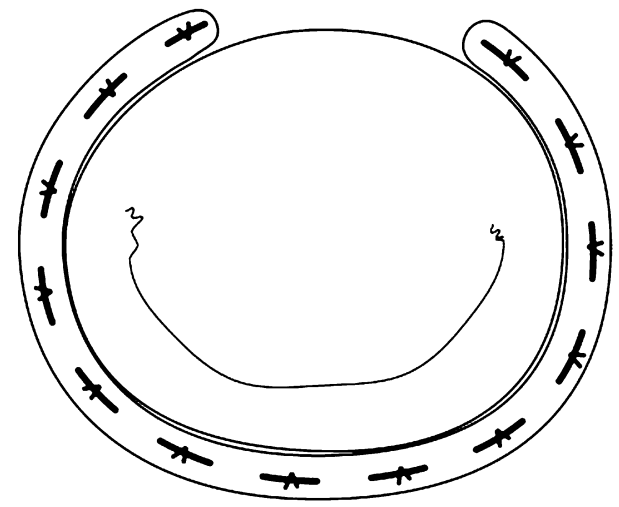

B

FIGURE 2. Schematic drawing of surgical procedure. A, Two concentric circles were drawn on expanded polytetrafluoroethylene cardiovascular patch, with inner diameter of $16 \mathrm{~mm}$ and outer diameter of $20 \mathrm{~mm}$. B, Then 2-mm wide expanded polytetrafluoroethylene ring was made. Partial ring was then fixed on mitral annulus with interrupted 3-0 braided polyester suture, thus reducing mitral valve diameter from 25 to 16 mm. 
mitral annulus, except in the intertrigone region. The saline solution test confirmed no leakage after the procedure. The patient was smoothly weaned from cardiopulmonary bypass after a bypass time of 76 minutes and an aortic crossclamp time of 33 minutes.

After surgery, the patient's blood pressure was 80 to 90 $\mathrm{mm} \mathrm{Hg}$, with a left atrial pressure of 8 to $10 \mathrm{~mm} \mathrm{Hg}$ and a central venous pressure of 10 to $12 \mathrm{~mm} \mathrm{Hg}$. He was extubated smoothly 2 days after surgery. Comparing the preoperative and postoperative (3 months after surgery) echocardiographic data, the LV end-diastolic diameter decreased from 4.0 to $3.4 \mathrm{~cm}$ (reference $2.6 \mathrm{~cm}$ ), the left atrial diameter decreased from $3.3 \mathrm{~cm}$ to $1.7 \mathrm{~cm}$, and the ejection fraction remained around $35 \%$ (Figure 1, B).

\section{DISCUSSION}

To our knowledge, this is the first report of mitral valve surgery on an infant with Barth syndrome and severe heart failure. Although we found no data on mitral valve surgery in patients with genetic cardiomyopathy, mitral valve plasty is used as a surgical alternative to heart transplant in patients with ischemic or dilated cardiomyopathy. In this patient, although the LV ejection fraction remained about $35 \%$, the left atrium and LV significantly decreased in size. This finding is consistent with the reverse remodeling of the LV that occurs after amelioration of MR. ${ }^{3}$

Planning of the mitral valve repair in this patient was based on echocardiographic findings. On long-axis views, the regurgitating jet came from noncoaptation of the anterior mitral leaflet (AML) and posterior mitral leaflet, the result of dilation of the annulus and tethering of the posterior mitral leaflet. The annular diameter was measured as $25 \mathrm{~mm}$, and the AML length was $20 \mathrm{~mm}$ (Figure 1, $A$ ). Because the reduction annuloplasty did not correct the tethering of the pos- terior mitral leaflet but rather augmented it, ${ }^{4}$ we needed to make the AML the sole functioning leaflet with good coaptation height. We therefore decided on a final annular diameter of $16 \mathrm{~mm}$, which would likely result in a zone of coaptation for the valve larger than $4 \mathrm{~mm}$. Postoperative echocardiography confirmed our expectation; the AML was the sole functioning leaflet after the surgery.

A commercially produced pediatric annular ring was unavailable. Although some surgeons use a pericardial strip to make a mitral ring for adults, ${ }^{5}$ we used a GORE-TEX patch to form a ring, which we thought would both be a fixed length and preserve some flexibility.

In conclusion, we report our experience with mitral valve repair in an infant with Barth syndrome and severe MR. On the basis of echocardiographic assessment and with surgical planning, reductive mitral annuloplasty was able to be used as an alternative to a heart transplant for this infant with severe MR and heart failure of genetic cardiomyopathy.

\section{References}

1. Spencer CT, Bryant RM, Day J, Gonzalez IL, Colan SD, Thompson WR, et al. Cardiac and clinical phenotype in Barth syndrome. Pediatrics. 2006;118: e337-46.

2. Mangat J, Lunnon-Wood T, Rees P, Elliott M, Burch M. Successful cardiac transplantation in Barth syndrome-single-centre experience of four patients. Pediatr Transplant. 2007;11:327-31

3. Westenberg JJ, van der Geest RJ, Lamb HJ, Versteegh MI, Braun J, Doornbos J, et al. MRI to evaluate left atrial and ventricular reverse remodeling after restrictive mitral annuloplasty in dilated cardiomyopathy. Circulation. 2005;112(9 Suppl): I437-42.

4. Kuwahara E, Otsuji Y, Iguro Y, Ueno T, Zhu F, Mizukami N, et al. Mechanism of recurrent/persistent ischemic/functional mitral regurgitation in the chronic phase after surgical annuloplasty: importance of augmented posterior leaflet tethering. Circulation. 2006;114(1 Suppl):I529-34.

5. Calafiore AM, Di Mauro M, Gallina S, Canosa C, Iaco AL. Optimal length of pericardial strip for posterior mitral overreductive annuloplasty. Ann Thorac Surg. 2003;75:1982-4. 